\title{
IGF-1 Mediates Exercise-Induced Phospholipid Alteration in the Murine Skin Tissues
}

\author{
Yu Jiang ${ }^{1}$, Haitian $\mathrm{Ma}^{2}$, Xiaoyu Su${ }^{1}$, Jie Chen ${ }^{1}$, Jianteng $\mathrm{Xu}^{1}$, Joseph Standard ${ }^{1}$, Dingbo Lin ${ }^{1}$ and Weiqun Wang ${ }^{1 *}$ \\ ${ }^{1}$ Department of Human Nutrition, Kansas State University, Manhattan, KS 66506, USA \\ ${ }^{2}$ College of Veterinary Medicine, Nanjing Agricultural University, Nanjing 210095, China
}

\begin{abstract}
We previously demonstrated that exercise with an iso-caloric diet significantly reduced body weight and skin carcinogenesis in correspondence with lower plasma IGF-1 levels and IGF-1-dependent phospholipid signaling. This study was thus designed to test the hypothesis that IGF-1 reduction plays a causal role in exercise-induced phospholipid changes. SENCAR mice were randomly assigned to one of the following three groups for 12 weeks: ad libitum-fed sedentary control, exercise but pair-fed the amount of the control (PE), and PE with IGF-1 injection (PE+IGF-1). Treadmill exercise was conducted at $13.4 \mathrm{~m} / \mathrm{min}$ for $90 \mathrm{~min} / \mathrm{d}, 5 \mathrm{~d} /$ week. In the last two weeks IGF1 was i.p. injected (10 $\mu \mathrm{g} / \mathrm{g}$ B.W.) twice per week. Both body weight and plasma IGF-1 levels were significantly reduced in PE mice when compared with the control. IGF-1 injection did not affect body weight, or the plasma levels of IGF-1 at the end of the experiment due to a rapid degradation with a half-life of $3.4 \mathrm{hrs}$. Of the 338 phospholipid species detected in the skin tissues by electron spray ionization tandem mass spectrometry, 21 were significantly changed in PE mice compared to control. Fourteen of the altered 21 species in PE mice were reversed by IGF-1 injection, including the most abundant phosphatidylinositol (PI) 38:4, a substrate for lipid PI3K signaling. Western Blot Analysis further showed the reduced PI3K, but not IGF-1R, in PE mice was also reversed by IGF-1 restoration. Overall, these data provided evidence that exercise-induced reduction of IGF-1 is required in mediating the alteration of phospholipid profile and PI-related PI3K signaling.
\end{abstract}

Keywords: Weight control; Exercise; IGF-1; Phospholipids; Mice

\section{Introduction}

Epidemiological, clinical, and experimental studies have revealed an inverse relationship of physical activity with the frequency of various cancers such as colorectal, pancreatic, breast, lung, skin, mammary, endometrial, and prostate cancer [1]. Thus, exercise-induced weight control has become an important strategy against cancer and other chronic diseases. The Nurses' Health Study found that moderate exercise such as brisk walking for 3 to 4 hrs per week was effective in preventing colon cancer [2]. It was also reported by the Women's Health Initiative that walking about $30 \mathrm{~min}$ per day could reduce breast cancer risk in postmenopausal women by up to $20 \%$ [3]. Furthermore, experimental animal studies have demonstrated that voluntary wheel running exercise inhibits UVB-induced skin tumorigenesis in mice [4]. The exercise-induced skin cancer inhibition has been associated with apoptosis in the epidermis via a p53-independent mechanism [5].

While physical activity has been suggested for cancer prevention, exercise-induced weight loss and cancer inhibition appears less consistent and/or less effective than dietary calorie restriction. Research by the Hursting group suggested that it was negative energy balance rather than exercise alone that inhibited the development of intestinal polyps in $\mathrm{APC}^{\mathrm{Min}}$ mice [6]. Our previous study found that exercise with an iso-caloric intake, but not exercise with ad libitum feeding, was effective in controlling body weight gain and selectively abrogating the tumor promoter TPA-induced PI3K-Akt pathway in the skin epidermis, resulting in enhanced apoptosis and reduced proliferation [7].

Many studies have investigated the molecular mechanisms of cancer prevention by physical activity. However, the underlying mechanisms have not been fully elucidated. Several proposed hypotheses include DNA repair, apoptosis regulation, oncogene inhibition and hormone alteration [8]. Alterations of the growth factor IGF-1-related signaling pathway seem to be one of the key mechanisms for weight-loss related cancer prevention.
IGF-1, a critical mediator modulating growth hormone, is known to stimulate cell proliferation, inhibit apoptosis, and induce tumorigenesis [9]. Prospective cohort studies have revealed that people with higher concentrations of IGF-I have an increased risk of developing several types of cancers $[10,11]$. Some further studies have shown that constitutive expression of IGF-1 and activation of IGF-1-dependent signaling in basal epithelial cells seems to play an important role in skin cancer development [12]. Squamous papillomas and carcinomas were found to develop spontaneously in BK5.IGF-1 transgenic mice, in which IGF-1 was over-expressed in the basal layer of skin epidermis [13]. IGF-1 receptor, which has a similar structure and function to insulin receptor, can modulate the physiological function of IGF-1; thus, it induces the phosphorylation of many intracellular proteins that then activates various signaling pathways including PI3K/Akt [1416]. The PI3K/Akt pathway has been found to play an important role in IGF-1-mediated tumor promotion. IGF-1-dependent PI3K activity significantly contributed to the tumor promoting role of IGF-1 in the epidermis of BK5.IGF-1 mice [17]. Our previous studies have found that exercise with an iso-caloric diet decreased the plasma levels of IGF1 with a corresponding down-expression of PI3K, phosphoserine Akt, and $\mathrm{p} 42 / \mathrm{p} 44-\mathrm{MAPK}$ [7]. These results suggested that IGF-1 reduction and inactive PI3K pathway might play an important role in cancer prevention by exercise-induced weight control.

${ }^{*}$ Corresponding author: Weiqun Wang, Department of Human Nutrition, Kansas State University, Manhattan, KS 66506, USA, E-mail: wwang@ksu.edu

Received May 11, 2012; Accepted June 25, 2012; Published June 30, 2012

Citation: Jiang Y, Ma H, Su X, Chen J, Xu J, Standard J (2012) IGF-1 Mediates Exercise-Induced Phospholipid Alteration in the Murine Skin Tissues. J Nutr Food Sci S2:003. doi:10.4172/2155-9600.S2-003

Copyright: () 2012 Jiang Y, et al. This is an open-access article distributed under the terms of the Creative Commons Attribution License, which permits unrestricted use, distribution, and reproduction in any medium, provided the original author and source are credited. 
Eukaryotic membranes contain as many as 1000 molecular species of phospholipids. Some phospholipids regulate the activities of enzymes, channels and transport proteins, as well as cell surface receptor that generates first and second messengers. Among these lipids, phosphatidylinositols (PIs) and its phosphorylated derivatives, phosphatidylinositol phosphates (referred to as phosphotinositides), have been found to play an important role in cellular signaling and intracellular trafficking [18]. PIs can be phosphorylated by PI kinases such as PI3K, which is activated by a variety of extra cellular signals including IGF-1 and tumor promoter TPA. PI $(3,4,5) \mathrm{P} 3$ or PIP3, the major product of $\mathrm{PI} 3 \mathrm{~K}$, is able to bind and activate Akt, thus activating many downstream signaling proteins that regulate cell survival and cell cycle progress [19]. Elevated levels of PIP3 and Akt have been found to be oncogenic and promote the transition to malignancy $[20,21]$. Phospholipid profiling changes including PIs can be monitored by "lipidomics" via electrospray ionization tandem mass spectrometry (ESI/MS-MS) [22,23] By using lipidomics, we previously detected the phospholipid profile of mouse skin tissues and found that exercise with pair-feeding significantly modified some phospholipid species, including a $36 \%$ to $75 \%$ decrease of certain PI species along with a significant reduction of PI3K [24]. Taken together, our previous observational studies and other studies indicated that exercise with an iso-caloric diet significantly reduces body weight and skin carcinogenesis in correspondence with a low level of plasma IGF-1 and IGF-1-dependent PI3K signaling [7,24].

To confirm a requirement of IGF-1 reduction in exercise-induced weight loss and phospholipid change, in this study IGF-1 levels were restored in exercised mice. The effects of IGF-1 restoration on phospholipid profile and IGF-1-dependent PI3K were assessed. This is of particular significance because it addresses the lack of direct evidence for IGF1 mediation exercise-induced alteration of phospholipid profile and PI3K-related signaling for cancer prevention.

\section{Materials and Methods}

\section{Animals and treatments}

Female SENCAR mice were purchased from NIH (Frederick, MD) at 6 weeks of age and randomly assigned into one of the following three groups for 12 weeks: ad libitum-fed AIN-93 diet and sedentary control (control), pair-feeding at the same amount as the control and treadmill exercise at $13.4 \mathrm{~m} / \mathrm{min}$ for $90 \mathrm{~min} / \mathrm{d}, 5 \mathrm{~d} /$ week (PE), PE plus IGF-1 injection (PE+IGF-1). Mice were kept individually with $40 \%$ humidity and 12-h light/dark cycle. To take into account the biological clocks of nocturnal rodents, the light cycle was adjusted for mice to run nighttime exercise. Body weight of each mouse was recorded twice per week. In the last two weeks, IGF-I (Novozymes GroPep, Australia) was administrated via i.p. injection (at $10 \mu \mathrm{g} / \mathrm{g}$ B.W.) twice per week. PE and the control mice were injected with saline vehicle (sham). The mice were fed until the last day, but exercise was stopped $24 \mathrm{hrs}$ before the mice were sacrificed by decapitation. The blood samples were collected and the dorsal skin samples were snap frozen in liquid nitrogen and then kept at $-70^{\circ} \mathrm{C}$ until further analysis.

For a pharmacokinetics study of plasma IGF-1, SENCAR mice at 6 weeks of age were acclimated for 1 week and then treated with IGF-1 by i.p. injection once at $10 \mu \mathrm{g} / \mathrm{g}$ body weight. Mice were sacrificed by decapitation at $0,1,2,6,12$, and $24 \mathrm{hrs}$ after injection, respectively. The plasma samples were prepared for IGF-1 analysis.

\section{Assessment of plasma IGF-1 levels}

Blood samples were obtained directly by decapitation and collected in heparin-coated tubes. Plasma was isolated by centrifugation at $1,000 \times \mathrm{g}$ for $10 \mathrm{~min}$ at $4^{\circ} \mathrm{C}$. Total IGF- 1 in plasma was extracted by acidETOH method and was measured by a RIA kit (ALPCO, NH).

\section{Assessment of protein levels by Western blotting}

Western blot analysis was performed as described previously $[7,24]$. Briefly, mouse skin tissues were homogenized in triton lysis buffer. Protein concentration was measured by a standard BCA assay (BioRad, Hercules, CA). An equal amount of $50 \mu \mathrm{g}$ of whole cell protein was electrophoresed on $10 \%$ SDS-poly-acrylamide gel. The protein bands were transferred to a nitrocellulose membrane, and then the transferred bands of PI3K (110 KDa), IGF-1R beta $(98 \mathrm{KDa})$, and $\beta$ actin $(43 \mathrm{kDa})$ were respectively bound to their monoclonal antibodies purchased from Santa Cruz Biotechnology Inc.(Santa Cruz, CA). The bound proteins were treated with the appropriate HRP-conjugated secondary antibody (Santa Cruz Biotechnology Inc., Santa Cruz, CA) and visualized by FluorChem ${ }^{\mathrm{TM}} 8800$ Advanced Imaging System (Alpha Innotech, San Leandro, CA). The relative density of the target band was normalized to the loading control $\beta$-actin and then expressed as a percentage of the controls.

\section{Lipid extraction and phospholipid profiling analysis}

Lipid extraction and phospholipid profiling analysis were performed as described previously [24]. In short, skin samples were ground with liquid nitrogen. After $2 \mathrm{~mL}$ of solvent [chloroform/ methanol $(1: 2 \mathrm{v} / \mathrm{v})+0.01 \%$ butylated hydroxytoluene] were mixed with $1 \mathrm{~g}$ of tissue, $1.25 \mathrm{~mL}$ chloroform and $1.25 \mathrm{~mL}$ water were added; the mixture was centrifuged at $1,000 \mathrm{rpm}$ for $15 \mathrm{~min}$, and the lower layer was collected. Then, $1.25 \mathrm{~mL}$ of chloroform was added to the tissue, the mixture was centrifuged, and the lower layer was removed and combined with the previously removed lower layer. The combined lower layers were analyzed for phospholipids using an automated electrospray ionization-tandem mass spectrometry approach. Data acquisition and analysis for acyl group identification were carried out as described previously $[22,25]$. Twelve phospholipid classes or subclasses, including PI, lysophosphatidylcholine (lysoPC), lysophosphatidylethanolamine (lysoPE), alk(en)yl/acyl phosphocholine (ePC), alk(en)yl/acyl phosphoethanolamine (ePE), and alk(en)yl/acyl phosphatidylserine (ePS), etc., were determined. Identification of phospholipid molecular species was based on total mass/charge and the presence of a fragment of mass/charge consistent with the head group class. The values less than 2 pmol or $0.002 \mathrm{~mol} \%$ are not in a linear range, indicating undetectable (UD).

\section{Statistical analysis}

The overall effects of treatments on body weight, IGF-1 levels, phospholipids, and Western blotting proteins were analyzed by one-way ANOVA with the least significant difference Fisher's LSD method. Data are expressed as means \pm S.E. The level of significance of all statistical tests is set at the $5 \%$ level by applying Dunnett's adjustment. All the statistical analyses were carried out with SAS 9.1 Software.

\section{Results}

\section{Effect of treadmill exercise with iso-caloric diet on body weight}

Body weights of mice during the total 12 weeks of experimentation are shown in Figure 1. Mice in the control group gradually gained weight throughout the experimental period $\mathrm{P}<0.05$ ), which began with $32.2 \pm 1.4 \mathrm{~g}$ and ended with $36.5 \pm 1.4 \mathrm{~g}$. The body weight of PE mice 


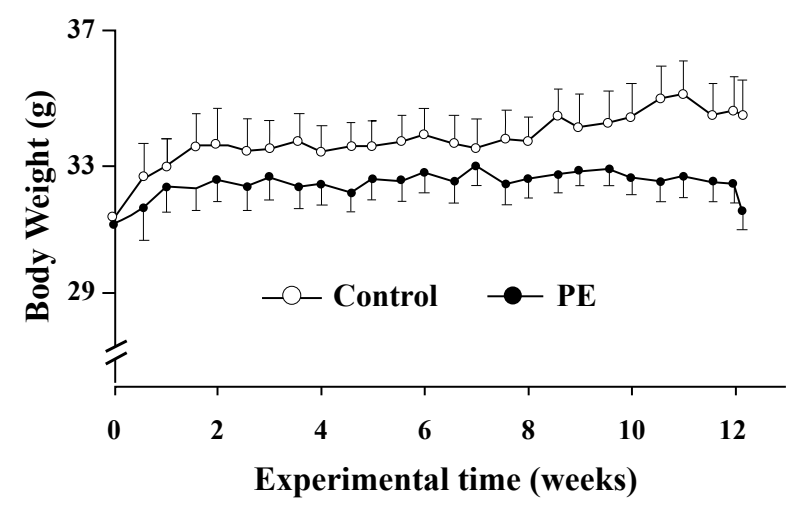

Figure 1: Effect of treadmill exercise with iso-caloric diet on body weight SENCAR mice at 6 weeks old were divided into ad libitum-fed sedentary control or pair-fed the same amount as the sedentary control. They performed treadmill exercise at $13.4 \mathrm{~m} / \mathrm{min}, 90 \mathrm{~min} / \mathrm{d}, 5$ days/week. Body weight was significantly lower in exercised mice, beginning in $2^{\text {nd }}$ week except for $7^{\text {th }}$ week in comparion with the controls. Results are means $\pm \mathrm{SE}, \mathrm{n}=8-12$.

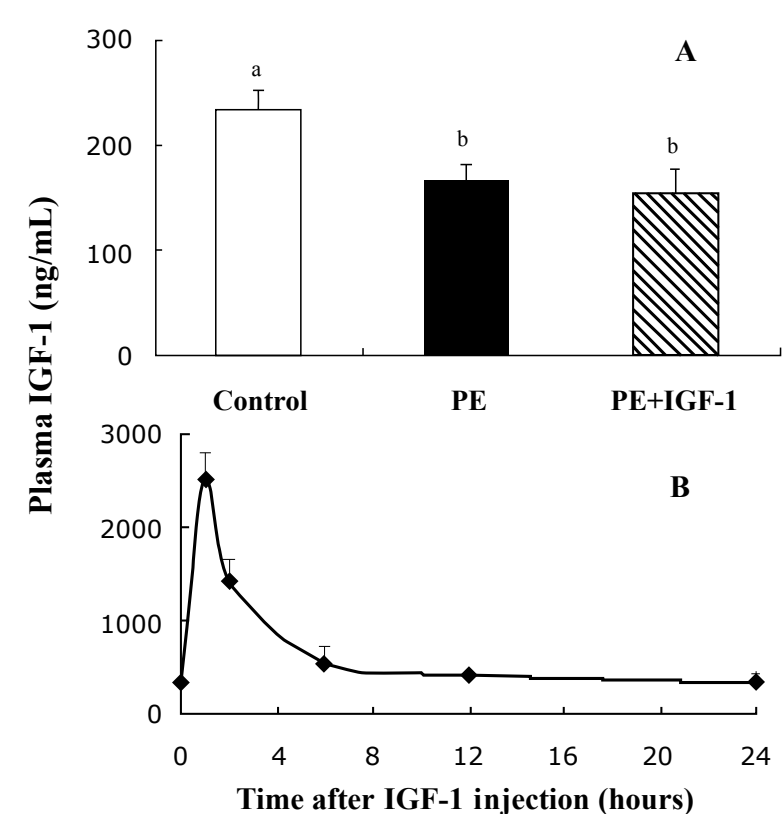

Figure 2: Impact of IGF-1 injection on plasma IGF-1 levels in SECAR mice A: SENCAR mice were exercised with iso-caloric diet for 12 weeks. IGF-I was injected at $10 \mu \mathrm{g} / \mathrm{g} \mathrm{B.W}$. twice per week in the last two weeks. Plasma IGF-1 levels were significantly lower in PE and PE+IGF-1 mice 24 hrs after the last IGF-1 injection (means with different letters differ significantly, $P$ $<0.05, n=5-8$. B: A pharmacokinetic study of plasma IGF-1 levels after injection of IGF-1 at $10 \mu \mathrm{g} / \mathrm{g}$ B.W. once showed the concentration of plasma IGF-1 increased, reaching a maximal concentration near $1 \mathrm{hr}$ after injection and then gradually declining to the basal level around $24 \mathrm{hrs}$ with a half-life of $3.4 \mathrm{hrs}$. Results are means $\pm \mathrm{SE}, \mathrm{n}=2-7$.

significantly changed during the whole experimental period, starting at $31.9 \pm 1.3 \mathrm{~g}$ and ending at $32.4 \pm 0.8 \mathrm{~g}$. When compared with the sedentary control, PE mice had significantly lowered body weight, beginning in $2^{\text {nd }}$ week except for $7^{\text {th }}$ week $(\mathrm{P}<0.05)$.

Effect of exercise with an iso-caloric diet and IGF-1 addition on plasma IGF-1 levels

As shown in Figure 2A, plasma IGF-1 levels were significantly reduced in both PE and PE+IGF-1 groups 24 hrs after the last IGF-1 injection when compared with the control counterparts $(\mathrm{P}<0.05)$.

Therefore, a pharmacokinetic study of plasma IGF-1 levels after IGF-1 injection in SENCAR mice was conducted and shown in Figure 2B. After injection of IGF-1 $(10 \mu \mathrm{g} / \mathrm{g}$ B.W $)$, the concentrations of plasma IGF-1 significantly increased, reaching a maximal concentration near 1 $\mathrm{hr}$ after injection and then gradually declining to the basal level around $24 \mathrm{hrs}$ with a half-life of $3.4 \mathrm{hrs}$.

\section{Effect of IGF-1 addition on phospholipid profile alteration}

A total of 338 phospholipid species were detectable by ESI/MS-MS in the mouse skin samples and 21 of them were found to be significantly different among the treatment groups. As shown in Table 1, the altered species of phospholipids include 3 PI, 4 lysoPC, 2 lysoPE, 1 ePC, 5 ePE and $6 \mathrm{ePS}$.

Three detected PI species were significantly altered in PE mice when compared with the sedentary control. Among these three altered PIs, 38:4-PI is the most abundant, representing $90 \%$ of the total PIs. The decrease of both 36:1-PI and 38:4-PI were statistically reversed by IGF-1 injection. Although all the detected 20:3-, 20:4-, 20:5-, and 22:5-lysoPC were not significantly different between PE and the control group, they significantly increased in IGF-1-injected group. Similarly, 20:4- and 22:5-lysoPE were not changed in PE mice but decreased by IGF-1 addition. The 36:1-ePC significantly increased in both PE and PE+IGF-1 mice, while the levels of 32:1- and 40:3-ePE increased in PE mice but reversed in PE+IGF-1 group. When compared with the control mice, the levels of 38:0-, 38:2-, 40:1-, and 40:4-ePS increased but 34:1- and 38:3-ePS decreased in PE group. It was noted that the addition of IGF-1 in PE mice significantly reversed the alteration of 38:0-, 38:3-, 40:1-, and 40:4-ePS.

\begin{tabular}{|c|c|c|c|c|c|}
\hline \multirow{2}{*}{$\begin{array}{l}\text { Phospholipid } \\
\text { group }\end{array}$} & \multirow[t]{2}{*}{ Species* } & \multirow[t]{2}{*}{$\mathrm{m} / \mathrm{z}$} & \multicolumn{3}{|c|}{ Mol $\%$ of total polar lipids ${ }^{\dagger}$} \\
\hline & & & Control & PE & $P E+I G F-1$ \\
\hline \multirow[t]{3}{*}{$\mathrm{PI}$} & $36: 1$ & 863.6 & $0.400 \pm 0.545^{\mathrm{a}}$ & $0.691 \pm 0.517^{b}$ & $0.113 \pm 0.134^{a}$ \\
\hline & $36: 3$ & 859.9 & $0.039 \pm 0.005^{\mathrm{a}}$ & $0.005 \pm 0.001^{b}$ & $U^{b}$ \\
\hline & $38: 4$ & 885.5 & $6.237 \pm 2.036^{a}$ & $4.383 \pm 0.681^{b}$ & $5.572 \pm 0.430^{\mathrm{a}, \mathrm{b}}$ \\
\hline \multirow[t]{4}{*}{ LysoPC } & $20: 3$ & 546.5 & UD $^{\mathrm{a}}$ & $0.003 \pm 0.002^{\mathrm{a}}$ & $0.028 \pm 0.017^{b}$ \\
\hline & $20: 4$ & 544.3 & $0.258 \pm 0.047^{a, b}$ & $0.137 \pm 0.012^{\mathrm{b}}$ & $0.343 \pm 0.110^{a}$ \\
\hline & $20: 5$ & 542.3 & UD $^{a}$ & $U^{a}$ & $0.006 \pm 0.004^{b}$ \\
\hline & $22: 5$ & 570.4 & $0.009 \pm 0.006^{\mathrm{a}, \mathrm{b}}$ & $U^{b}$ & $0.023 \pm 0.019^{a}$ \\
\hline \multirow[t]{2}{*}{ LysoPE } & $20: 4$ & 502.3 & $0.013 \pm 0.006^{\mathrm{a}, \mathrm{b}}$ & $0.024 \pm 0.004^{a}$ & $0.006 \pm 0.004^{b}$ \\
\hline & $22: 5$ & 528.3 & $0.007 \pm 0.004^{\mathrm{a}, \mathrm{b}}$ & $0.009 \pm 0.005^{a}$ & $U^{b}$ \\
\hline ePC & $36: 1$ & 774.6 & $0.204 \pm 0.053^{a}$ & $0.316 \pm 0.036^{b}$ & $0.323 \pm 0.048^{b}$ \\
\hline \multirow[t]{5}{*}{ ePE } & $32: 1$ & 676.5 & UD $^{\mathrm{a}}$ & $0.005 \pm 0.002^{\mathrm{b}}$ & $U^{\mathrm{a}}$ \\
\hline & $38: 1$ & 760.6 & $0.010 \pm 0.006^{a, b}$ & $U^{b}$ & $0.024 \pm 0.008^{a}$ \\
\hline & $38: 2$ & 758.6 & $0.357 \pm 0.008^{a}$ & $0.496 \pm 0.044^{b}$ & $0.481 \pm 0.018^{b}$ \\
\hline & $40: 3$ & 784.6 & $U^{a}$ & $0.008 \pm 0.004^{b}$ & $U^{a}$ \\
\hline & $40: 4$ & 782.6 & $0.073 \pm 0.005^{a}$ & $0.163 \pm 0.020^{b}$ & $0.159 \pm 0.006^{a}$ \\
\hline \multirow[t]{6}{*}{ ePS } & $34: 1$ & 746.5 & $0.021 \pm 0.010^{\mathrm{a}}$ & $0.009 \pm 0.005^{a, b}$ & UD $^{\mathrm{b}}$ \\
\hline & $38: 0$ & 804.5 & UD $^{a}$ & $0.011 \pm 0.004^{b}$ & $U^{a}$ \\
\hline & $38: 2$ & 800.6 & $0.026 \pm 0.018^{a}$ & $0.071 \pm 0.016^{b}$ & $0.061 \pm 0.018^{b}$ \\
\hline & $38: 3$ & 798.6 & $0.003 \pm 0.002^{a, b}$ & $U^{b}$ & $0.011 \pm 0.005^{a}$ \\
\hline & $40: 1$ & 830.5 & $0.011 \pm 0.008^{a, b}$ & $0.044 \pm 0.014^{a}$ & $U^{b}$ \\
\hline & $40: 4$ & 824.6 & $0.016 \pm 0.010^{a}$ & $0.052 \pm 0.012^{b}$ & $0.046 \pm 0.024^{a, b}$ \\
\hline
\end{tabular}

${ }^{*}$ Total acyl carbons:total double bonds (UD: undetectable values if less than 0.002 $\mathrm{mol} \%$ );

†Results are means \pm SE ( $n=5-7$ per group). Means with different letters differ significantly, $\mathrm{P} \leq 0.05$.

Table 1: Effects of restoration IGF-1 on the profile of phospholipids in the mouse skin tissues. 

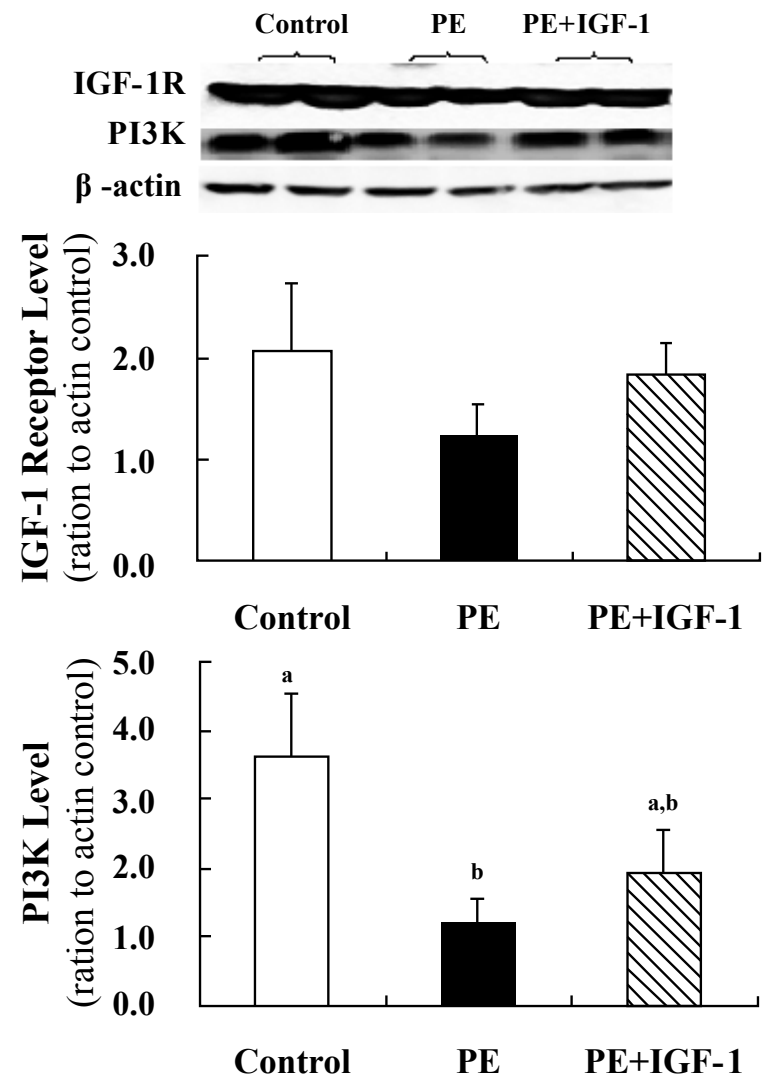

Figure 3: Impact of IGF-1 addition on exercise-induced expression of IGF-1 receptor and $\mathrm{PI} 3 \mathrm{~K}$ in mouse skin tissues. SENCAR mice were exercised with an iso-caloric diet for 12 weeks. IGF-I was injected at $10 \mu \mathrm{g} / \mathrm{g} \mathrm{B.W}$. twice per week in the last two weeks. The levels of IGF-1 receptor and PI3K protein in skin tissues was determined by Western blotting and quantified by the FluorChem 8800 Advanced Imaging System. No statistical difference of the levels of IGF-1 receptor between treatment groups was found. The levels of $\mathrm{PI} 3 \mathrm{~K}$ expression was significantly decreased in PE group, but that reduction was reversed by IGF-1 addition (means with different letters differ significantly, $P<0.05, n=5-7$.

\section{Effect of IGF-1 addition on IGF-1 receptor and PI3K protein expression}

The expression levels of IGF-1 receptor and PI3K protein in mouse skin samples as measured by Western blotting analysis are shown in Figure 3 . While the expression of IGF-1 receptor was not significantly different between treatment groups, the expression of PI3K was decreased in PE mice. Furthermore, the significant decrease of PI3K expression in PE mice was reversed by IGF-1 addition.

\section{Discussion}

We previously demonstrated that exercise with an iso-caloric diet significantly reduced body weight in correspondence with a decrease of plasma IGF-1 and IGF-1-dependent PI3K/Akt signaling [7]. We also found a significant modification of phospholipid profile by exercise with an iso-caloric intake occurred in the skin epidermis, which might be related to the reduced PI3K activity [24]. To further confirm a causal requirement of IGF-1 reduction for a mechanistic understanding of exercise-induced skin cancer prevention, the present study was conducted to investigate the effects of IGF-1 restoration on phospholipid profile and PI3K expression.
The body weight significantly decreased by treadmill exercise with an iso-caloric diet when compared with the sedentary counterparts (Figure 1), which is consistent with our reports and others [7,24,26,27]. As expected, plasma IGF-1 levels were significantly lower in exerciseinduced weight loss mice (Figure 2A). Reduction of the plasma IGF1 levels has been intensively reported in weight controlled animal models, especially in dietary calorie restriction-induced weight loss. For example, serum IGF-1 levels are usually found to drop down to half in $40 \%$ dietary calorie restricted rats or $74 \%$ in $20 \%$ dietary calorie restricted p53-deficient mice [28-31]. The influence of exercise on plasma IGF-1 levels is somewhat complicated, but it seems to be related to dietary calorie intake. It was found that the plasma IGF-1 levels did not decrease either by short bout exercise or physical training in adults [32]. In rodent models, both our studies and others found that exercise with ad libitum feeding was not sufficient to decrease plasma IGF-1 levels $[7,33]$. When the exercised mice were fed an iso-caloric diet as their sedentary counterpart, the plasma levels of IGF-1 were significantly reduced [7].

However, IGF-1 injection did not restore the plasma levels of IGF-1 in PE mice (Figure 2A). To illustrate this discrepancy, a pharmacokinetics of IGF-1 injection was further studied. After injection of IGF-1, the concentration of plasma IGF-1 increased, reaching a maximal concentration near $1 \mathrm{hr}$ after injection and then gradually declining to the basal level around $24 \mathrm{hrs}$ with an elimination half-life of $3.4 \mathrm{hrs}$ (Figure 2B). Since the IGF-1-injected mice were sacrificed $24 \mathrm{hrs}$ after the last IGF-1 injection, it might not be unexpected that the IGF-1 levels in PE+IGF-1 mice were not significantly changed. Although the plasma levels of IGF-1 in the exercised mice were not significantly changed $24 \mathrm{hrs}$ after injection, acute elevation of plasma IGF-1 levels through multiple injections still significantly modified the altered phospholipids in PE mice (Table 1) and PI3K protein expression (Figure 3).

As shown in Table 1, two of the three altered phospholipid PIs, including the most abundant 38:4-PI in PE mice, were reversed in PE+IGF-1 mice. PIs have been associated with many biological functions such as lipid PI3K signaling [34,35], this change by interaction between exercise and IGF-1 restoration is in agreement with our previous report [24]. In addition to PIs, four lysoPCs and two lysoPEs were modified with injection of IGF-1. Lysophospholipids have been suggested to have a role related to cell signaling. LysoPC could bind to G-protein coupled receptors, leading to the activation of protein kinase $\mathrm{C}$ and mitogen-activated protein kinase signaling [36,37]. Modification of lysoPC has been characterized in inflammation-related disease and a decrease of lysoPC levels may prevent cancer and/or atherogenesis by reducing cellular damage and proliferation [38-40]. Furthermore, the present study also found some ether phospholipids species, such as 32:1-ePE, 38:1-ePE, 40:3-ePE, 38:0-ePS, and 40:4-ePS, which were also significantly changed by IGF- 1 addition. It should be noted that some of the identified phospholipids might be ambiguous due to same $\mathrm{m} / \mathrm{z}$ and same head group. For instance, 38:1-ePE could be 38:8-PE, 38:2-ePE could be 38:9 PE, 38:0-ePS could be 38:7-PS, 38:2-ePS could be 38:9PS, and 40:1-ePS could be 40:8-PS. Furthermore, some phospholipid changes were in compounds of low abundance, detected near the high $\mathrm{m} / \mathrm{z}$ end of clusters of MS peaks containing more abundant compounds, suggesting that any issue with the isotopic deconvolution of the cluster might cause a false change. Some phospholipid changes are not same as we reported previously [24], which may be, at least in part, due to a different mouse strain used. While the functional impact of exercise on the most of these phospholipid species is not fully defined, future 
Citation: Jiang Y, Ma H, Su X, Chen J, Xu J, Standard J (2012) IGF-1 Mediates Exercise-Induced Phospholipid Alteration in the Murine Skin Tissues. J Nutr Food Sci S2:003. doi:10.4172/2155-9600.S2-003

studies focused on the combined interaction of IGF-1 on cancer-related lipid signalings may be warranted.

A clear understanding of a potential impact of exercise on phospholipids appears to be PIs-related PI3k signaling. In addition to being membrane structural building blocks, PIs and their derivatives like PIP3 have been found to play an important role in cellular signaling and intracellular trafficking [17]. It has been demonstrated that elevating levels of PIP3, a major product of PI3K, has been able to activate Akt and promote the transition to malignancy [18-20]. An activated PI3K usually phosphorylates PIs in the cell membrane to produce PIP3 and activate a series of downstream proteins for cell survival and progress. Therefore, a significant impact of exercise with or without IGF-1 addition on PIs, especially the most abundant PI 38:4 may be related to PI3K activity. It is interesting that the restoration of IGF-1 in this study statistically abolished the reduction of PI3K rather than IGF-1R in PE mice (Figure 3). Considering the importance of PI3K in IGF-1-mediated skin cancer promotion, the present study not only demonstrates that the reduced expression of PI3K in PE mice is significantly abrogated by IGF-1 addition, but also provides direct evidence that IGF-1 mediates the exercise-induced PIs and PI-related PI3K changes. Besides, it would also be interesting to investigate the effects of the IGF-1 injection in normal mice without exercise as an appropriate control.

In summary, the results of this study showed that treadmill exercise with an iso-caloric intake could control body weight and reduce plasma IGF-1 levels. The reduced IGF-1 levels seem to be required for the changes of certain phospholipid species including PIs and PIs-associated PI3K expression. Therefore, these data provide first time evidence that exercise-induced reduction of IGF-1 appear to be required in mediating the alteration of phospholipid profile and PI-related PI3K signaling.

\section{Acknowledgments}

This work was supported in part by grants from the NCI R15CA167678, NIHINBRE P20RR16475, and NCI R01CA106397 (to Weiqun Wang). A graduate student travel award (to Yu Jiang) and undergraduate student cancer research award (to Xiaoyu Su) were supported by the Terry Johnson Center for Basic Cancer Research, Kansas State University. The lipid analysis described in this work were performed at the Kansas Lipidomics Research Center with support from KSU's Targeted Excellence Program, employing method development and instruments acquired by support from NSF-EPS0236912, MCB0455318, and DBI0521587, Kansas Technology Enterprise Corporation, and NIH-INBRE P20RR16475. The authors would also like to thank Ms. May Roth for assistance in lipidomics analysis This is a journal contribution \#12-220-J of the Kansas Agricultural Experiment Station

\section{References}

1. Na HK, Oliynyk S (2011) Effects of physical activity on cancer prevention. Ann N Y Acad Sci 1229: 176-183.

2. Martínez ME, Giovannucci E, Spiegelman D, Hunter DJ, Willett WC, et al. (1997) Leisure-time physical activity, body size, and colon cancer in women. Nurses' Health Study Research Group. J Natl Cancer Inst 89: 948-955.

3. McTiernan A, Kooperberg C, White E, Wilcox S, Coates R, et al. (2003) Recreational physical activity and the risk of breast cancer in postmenopausal women: the Women's Health Initiative Cohort Study. JAMA 290: 1331-1336.

4. Michna L, Wagner GC, Lou YR, Xie JG, Peng QY, et al. (2006) Inhibitory effects of voluntary running wheel exercise on UVB-induced skin carcinogenesis in SKH-1 mice. Carcinogenesis 27: 2108-2115.

5. Lu YP, Lou YR, Nolan B, Peng QY, Xie JG, et al. (2006) Stimulatory effect of voluntary exercise or fat removal (partial lipectomy) on apoptosis in the skin of UVB light-irradiated mice. Proc Natl Acad Sci U S A 103: 16301-16306.

6. Colbert LH, Mai V, Tooze JA, Perkins SN, Berrigan D, et al. (2006) Negative energy balance induced by voluntary wheel running inhibits polyp development in APCMin mice. Carcinogenesis 27: 2103-2107.
7. Xie L, Jiang Y, Ouyang P, Chen J, Doan H, et al. (2007) Effects of dietary calorie restriction or exercise on the PI3K and Ras signaling pathways in the skin of mice. J Biol Chem 282: 28025-28035.

8. Thompson HJ, Jiang W, Zhu Z (2009) Candidate mechanisms accounting fo effects of physical activity on breast carcinogenesis. IUBMB Life 61: 895-901.

9. Werner H, Le Roith D (2000) New concepts in regulation and function of the insulin-like growth factors: implications for understanding normal growth and neoplasia. Cell Mol Life Sci 57: 932-942.

10. Chan JM, Stampfer MJ, Giovannucci E, Gann PH, Ma J, et al. (1998) Plasma insulin-like growth factor-I and prostate cancer risk: a prospective study. Science 279: 563-566.

11. Ma J, Pollak MN, Giovannucci E, Chan JM, Tao Y, et al. (1999) Prospective study of colorectal cancer risk in men and plasma levels of insulin-like growth factor (IGF)-I and IGF-binding protein-3. J Natl Cancer Inst 91: 620-625.

12. Rho O, Bol DK, You J, Beltrán L, Rupp T, et al. (1996) Altered expression of insulin-like growth factor I and its receptor during multistage carcinogenesis in mouse skin. Mol Carcinog 17: 62-69.

13. DiGiovanni J, Bol DK, Wilker E, Beltrán L, Carbajal S, et al. (2000) Constitutive expression of insulin-like growth factor- 1 in epidermal basal cells of transgenic mice leads to spontaneous tumor promotion. Cancer Res 60: 1561-1570.

14. Butler AA, Yakar S, Gewolb IH, Karas M, Okubo Y, et al. (1998) Insulin-like growth factor-I receptor signal transduction: at the interface between physiology and cell biology. Comp Biochem Physiol B Biochem Mol Biol 121: 19-26.

15. LeRoith D, Werner H, Beitner-Johnson D, Roberts CT Jr (1995) Molecular and cellular aspects of the insulin-like growth factor I receptor. Endocr Rev 16: 143 163.

16. Foncea R, Andersson M, Ketterman A, Blakesley V, Sapag-Hagar M, et al. (1997) Insulin-like growth factor-I rapidly activates multiple signal transduction pathways in cultured rat cardiac myocytes. J Biol Chem 272: 19115-19124.

17. Wilker E, Lu J, Rho O, Carbajal S, Beltrán L, et al. (2005) Role of PI3K/Ak signaling in insulin-like growth factor-1 (IGF-1) skin tumor promotion. Mol Carcinog 44: 137-145.

18. Krauss M, Haucke V (2007) Phosphoinositide-metabolizing enzymes at the interface between membrane traffic and cell signalling. EMBO Rep 8: 241-246.

19. Cantley LC (2002) The phosphoinositide 3-kinase pathway. Science 296: 16551657.

20. Engelman JA, Luo J, Cantley LC (2006) The evolution of phosphatidylinosito 3-kinases as regulators of growth and metabolism. Nat Rev Genet 7: 606-619.

21. Manning BD, Cantley LC (2007) AKT/PKB signaling: navigating downstream. Cell 129: $1261-1274$

22. Welti R, Wang X (2004) Lipid species profiling: a high-throughput approach to identify lipid compositional changes and determine the function of genes involved in lipid metabolism and signaling. Curr Opin Plant Biol 7: 337-344.

23. Wenk MR (2005) The emerging field of lipidomics. Nat Rev Drug Discov 4 594-610.

24. Ouyang P, Jiang Y, Doan HM, Xie L, Vasquez D, et al. (2010) Weight Loss via exercise with controlled dietary intake may affect phospholipid profile for cancer prevention in murine skin tissues. Cancer Prev Res (Phila) 3: 466-477.

25. Bartz R, Li WH, Venables B, Zehmer JK, Roth MR, et al. (2007) Lipidomics reveals that adiposomes store ether lipids and mediate phospholipid traffic. $J$ Lipid Res 48: 837-847.

26. Moore T, Beltran L, Carbajal S, Strom S, Traag J, et al. (2008) Dietary energy balance modulates signaling through the Akt/mammalian target of rapamycin pathways in multiple epithelial tissues. Cancer Prev Res (Phila) 1: 65-76.

27. Jiang Y, Wang W (2008) Potential mechanisms of cancer prevention by weight control. Biophysical Reviews and Letters 3: 421-437.

28. Dunn SE, Kari FW, French J, Leininger JR, Travlos G, et al. (1997) Dietary restriction reduces insulin-like growth factor I levels, which modulates apoptosis, cell proliferation, and tumor progression in p53-deficient mice. Cancer Res 57: 4667-4672.

29. Zhu Z, Jiang W, McGinley J, Wolfe P, Thompson HJ (2005) Effects of dietary energy repletion and IGF-1 infusion on the inhibition of mammary carcinogenesis by dietary energy restriction. Mol Carcinog 42: 170-176. 
Citation: Jiang Y, Ma H, Su X, Chen J, Xu J, Standard J (2012) IGF-1 Mediates Exercise-Induced Phospholipid Alteration in the Murine Skin Tissues. J Nutr Food Sci S2:003. doi:10.4172/2155-9600.S2-003

Page 6 of 6

30. Ruggeri BA, Klurfeld DM, Kritchevsky D, Furlanetto RW (1989) Caloric restriction and 7,12-dimethylbenz(a)anthracene-induced mammary tumor growth in rats: alterations in circulating insulin, insulin-like growth factors I and II, and epidermal growth factor. Cancer Res 49: 4130-4134.

31. Hursting SD, Switzer BR, French JE, Kari FW (1993) The growth hormone: insulin-like growth factor 1 axis is a mediator of diet restriction-induced inhibition of mononuclear cell leukemia in Fischer rats. Cancer Res 53: 2750-2757.

32. Kaaks R (2004) Nutrition, insulin, IGF-1 metabolism and cancer risk: a summary of epidemiological evidence. Novartis Found Symp 262: 247-260.

33. Bravenboer N, Engelbregt MJ, Visser NA, Popp-Snijders C, Lips $P$ (2001) The effect of exercise on systemic and bone concentrations of growth factors in rats. J Orthop Res 19: 945-949.

34. Augert G, Blackmore PF, Exton JH (1989) Changes in the concentration and fatty acid composition of phosphoinositides induced by hormones in hepatocytes. J Biol Chem 264: 2574-2580.

35. Postle AD, Dombrowsky H, Clarke H, Pynn CJ, Koster G, et al. (2004) Mass spectroscopic analysis of phosphatidylinositol synthesis using 6-deuteriated- myo-inositol: comparison of the molecular specificities and acyl remodelling mechanisms in mouse tissues and cultured cells. Biochem Soc Trans 32: 10571059.

36. Prokazova NV, Zvezdina ND, Korotaeva AA (1998) Effect of lysophosphatidylcholine on transmembrane signal transduction. Biochemistry (Mosc) 63: 31-37

37. Xu Y (2002) Sphingosylphosphorylcholine and lysophosphatidylcholine: G protein-coupled receptors and receptor-mediated signal transduction. Biochim Biophys Acta 1582: 81-88.

38. Quinn MT, Parthasarathy S, Steinberg D (1988) Lysophosphatidylcholine: a chemotactic factor for human monocytes and its potential role in atherogenesis. Proc Natl Acad Sci U S A 85: 2805-2809.

39. Okita M, Gaudette DC, Mills GB, Holub BJ (1997) Elevated levels and altered fatty acid composition of plasma lysophosphatidylcholine(lysoPC) in ovarian cancer patients. Int J Cancer 71: 31-34

40. Sasagawa S, Yamamoto A, Ichimura T, Omata S, Horigome T (1999) In vitro nuclear assembly with affinity-purified nuclear envelope precursor vesicle fractions, PV1 and PV2. Eur J Cell Biol 78: 593-600.
This article was originally published in a special issue, Dietary factors for cancer prevention handled by Editor(s). Dr. Weiqun (George) Wang, Kansas State University, Barton
Submit your next manuscript and get advantages of OMICS Group submissions

Unique features:

- User friendly/feasible website-translation of your paper to 50 world's leading languages

Audio Version of published paper

Digital articles to share and explore

Special features:

200 Open Access Journals

15,000 editorial team

21 days rapid review process

Quality and quick editorial, review and publication processing

Indexing at PubMed (partial), Scopus, DOAJ, EBSCO, Index Copernicus and Google Scholar etc

Sharing Option: Social Networking Enabled

- Authors, Reviewers and Editors rewarded with online Scientific Credits

Better discount for your subsequent articles

Submit your manuscript at: http://www.editorialmanager.com/lifescience 